Jens-Hinrich Binder

\title{
Regulierungsinstrumente und Regulierungsstrategien im Kapitalgesellschaftsrecht
}

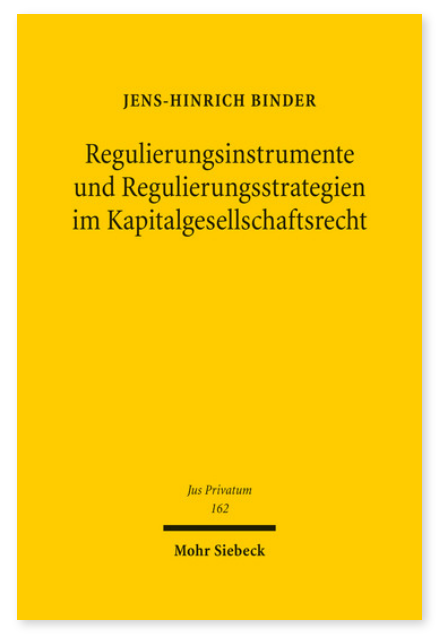

2012. XXXI, 623 Seiten. JusPriv 162

ISBN 978-3-16-152085-3

DOI 10.1628/978-3-16-152085-3

eBook PDF 159,00€

ISBN 978-3-16-150848-6

Leinen $159,00 €$
Jens-Hinrich Binder nimmt rechtstheoretische und rechtsökonomische Aspekte zur Wirkung von Rechtsnormen auf und entwickelt sie zu Vorstudien einer Rechtsetzungslehre für das Kapitalgesellschaftsrecht. Zunächst untersucht er theoretisch, dann historisch-vergleichend die Rechtsentwicklung in Deutschland, England, Frankreich und den USA sowie deren unterschiedliche Regulierungsinstrumente und entwickelt Aussagen zu jeweils strukturimmanenten Funktionsmerkmalen. Dabei entsteht eine Art dynamisches Regulierungsmodell, das eine kontinuierliche Anpassung bestehender Regelprogramme im kooperativen Ausgleich von gesetzlicher und privater Regulierung befürwortet. Ausschlaggebend für die Verteilung der Regelungsverantwortung ist danach die Verteilung hinreichender Information über das zu regelnde Sachproblem zwischen den Ebenen der Regelsetzung und -durchsetzung; den Schlüssel für die Allokation der Regelungsverantwortung bietet die Auswahl der zur Verfügung stehenden Regulierungsinstrumente.

Jens-Hinrich Binder ist Inhaber des Lehrstuhls für Bürgerliches Recht, Handels- und Wirtschaftsrecht, insbes. Gesellschaftsund Kapitalmarktrecht an der Eberhard-Karls-Universität Tübingen.

Jetzt bestellen:

https://mohrsiebeck.com/buch/regulierungsinstrumente-und-regulierungsstrategien-im-kapitalgesellschaftsrecht-

9783161520853?no_cache=1

order@mohrsiebeck.com

Telefon: +49 (0)7071-923-17

Telefax: $+49(0) 7071-51104$ 